\title{
Design, Development and Characterization of Nano Structured Lipid Carrier for Topical Delivery of Aceclofenac
}

\author{
Naglakshmi Sethuraman*, Shanmuganathan S, Sandhya K, Anbarasan B
}

Department of Pharmaceutics, Faculty of Pharmacy, Sri Ramachandra Medical College and Research Institute, Chennai 600116, Tamil Nadu, INDIA.

\begin{abstract}
Objective: Aceclofenac is non steroidal anti inflammatory drug (NSAID) and is considered to be first line drug in treatment of rheumatoid arthritis, osteo arthritis and ankylosing spondylitis. Aceclofenac undergoes first pass metabolism when taken orally and it also produces some Gl problems. The limitations of oral administration have been overcome by topical route. Drug aceclofenac has been loaded with lipid carriers and then formulated in to topical formulation with the objective of prolonging its action and avoiding its most side effects by incorporation of solid lipid carriers which is achieved by Nanostructured lipid carrier (NLC). Methods: Nanostructured lipid carrier was prepared by Ultra sonication or High Speed Homogenization method. Results and Discussion: Characterization of nanostructured lipid carrier was performed by measuring particle size, drug entrapment efficiency and in-vitro drug release. Spherical uniform particles (size below $500 \mathrm{~nm}$ ), Drug entrapment efficiency was found to be in the range of about $75-85 \%$. The drug release profile of all the formulations after $8 \mathrm{~h}$ study was found to be in the range of $40 \%-78 \%$. Formulation showing sustained release profile at the end of the study was found to be the best formulation. Optimized formulation was converted in to Topical gel with Carbopol as gelling agent was formulated and characterized for its physical appearance, $\mathrm{pH}$, viscosity, spreadability, homogeneity studies. Conclusion: The result concludes that aceclofenac loaded nanostructured lipid carrier could be a potential drug delivery system for topical applications.
\end{abstract}

Key words: Aceclofenac, Ultra sonication, High speed homogenization, Entrapment efficiency, in-vitro release studies.

\section{INTRODUCTION}

Nanostructure lipid carriers (NLC) are the novel colloidal carriers in the new generation of lipid nanoparticles which have been gaining attention in recent trends. Solid lipid Nano particles have been administrated through several routes such as parenteral, oral and topical routes by controlled and sustained release formulations. It has to be explored for its delivery in commercial market. ${ }^{1}$ Some of the advantages of this drug delivery includes controlled release profile, drug targeting, high stability, good entrapment efficiency, incorporation of both lipophilic and hydrophilic drug, non biotoxicity of the carrier, avoidance of organic solvents, good scalability and also this system is attractive for their potential to improve performance of pharmaceuticals, nutraceuticals and other materials. There are different techniques employed for preparation of SLN particles like modified high shear homogenization, ultrasound techniques, emulsification diffusion, solvent injection, solvent diffusion, micro emulsion, hot
Submission Date: 27-07-2017; Revision Date: 25-09-2017; Accepted Date: 18-04-2018

DOI: 10.5530/ijper.52.4.67 Correspondence: Nagalakshmi Sethuraman, Assistant Professor, Department of Pharmaceutics, Faculty of Pharmacy, Sri Ramachandra Medical College and Research Institute (Deemed to be University), Chennai 600116, Tamil Nadu, INDIA. Phone: 91-9176468060 E-mail: nagalakshmimpharm@gmail.com

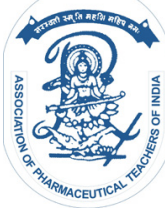

www.ijper.org 
homogenization and currently membrane contractor technique was employed. ${ }^{2}$

Aceclofenac is a non-steroidal anti-inflammatory drug (NSAID) used in the first line treatment of rheumatoid arthritis, osteo arthritis and ankylosing spondylitis. Aceclofenac is partially water insoluble drug which undergoes first pass metabolism when taken orally also it produces some GI problems. Hence better alternate route of administration of aceclofenac is transdermal route. Encapsulation of aceclofenac in to nano structured lipid carrier with the objective of prolonging its action and avoiding its most side effect. ${ }^{3}$ As this dosage forms would reduce the frequency of dosing resulting in better therapeutic effect and hence better patient compliance could be achieved. The present research work was aimed to formulate and evaluate the site specific delivery of aceclofenac as nano structured lipid carriers for topical delivery by using ultra sonication technique. Six formulations with varying lipid concentrations were studied to optimize the formulation for its maximum entrapment efficiency (EE), drug release and particle size. The optimized formulation showing sustained release with good entrapment efficiency was converted in to topical gel and its characteristic studies were performed. ${ }^{4}$

\section{MATERIALS AND METHOD}

\section{MATERIALS}

Aceclofenac was obtained from as a gift sample from Fourtt's India Limited, Chennai. Stearic acid, Oleic acid, Phospholipon $90 \mathrm{H}$, Carbopol $940 \mathrm{P}$ was purchased from Himedia and other reagents used were of analytical grade.

\section{Method for preparation of Nanostructured lipid carrier (NLC) \\ Preparation of Aceclofenac loaded NLC's ${ }^{5,6}$ \\ Ultrasonication method or High speed homogenizer method}

Aceclofenac and Phospholipon $90 \mathrm{H}$ were dissolved in methanol and mixed with an acetone solution containing a blend of stearic acid and oleic acid. The mixture was then added drop wise to Tween 80 at $70^{\circ} \mathrm{C}$ a pre emulsion was obtained by homogenization at $15000 \mathrm{rpm}$ and ultrasonicate for $10 \mathrm{~min}$ at $70^{\circ} \mathrm{C}$. Further, this pre emulsion was ultra sonicated for $15 \mathrm{~min}$ to prevent the crystallization of lipids. The o/w emulsion obtained was subsequently cooled down to room temperature with continuous stirring and the lipid was recrystallized to form Nanostructured lipid carrier (NLC). The obtained NLC dispersions were lyophilized and used for further characterization studies. The formulation of different ingredients with the composition was listed in the Table 1.

\section{Characterization of Prepared Nanostructured lipid carrier (NLC'S) $7,8,9$}

\section{Fourier Transforms-Infra Red (FT-IR) studies}

FT- IR spectrum studies helps to confirm the identity of the drug and to detect the interaction of the drug with polymers. FT- IR spectral measurement for pure aceclofenac drug, lipids, phospholipon $\mathrm{H}$, physical mixture and drug loaded NLC dispersion were carried out in order to find out the incompatibility study.

\section{Drug Entrapment Efficiency}

A volume of $2 \mathrm{ml}$ of each drug loaded sample was centrifuged at $12500 \mathrm{rpm}$ for $45 \mathrm{~min}$ to separate the lipid and aqueous phase. The supernatant was then diluted with methanol filtered through $40 \mu \mathrm{m}$ filter paper and the drug content was determined by the UV- VIS spectrophotometer. The entrapment efficiency of NLC was calculated as

$$
\begin{gathered}
\% \text { Entrapment Efficiency }(\mathrm{EE})=\frac{(\mathrm{Wa}-\mathrm{Ws})}{\mathrm{Wa}} \times 100 \\
\text { Drug loading }(\mathrm{DL})=\frac{(\mathrm{Wa}-\mathrm{Ws})}{(\mathrm{Wa}-\mathrm{Ws}+\mathrm{Wl})} \times 100
\end{gathered}
$$

Where EE is entrapment efficiency, DL is drug loading, Wa stands for the mass of aceclofenac added to the formulation, and Ws - analyzed weight of the drug in supernatant and W 1 - weight of lipid added.

\section{In vitro release study of Nanostructured lipid carrier (NLC)}

The in vitro release studies were performed using Franz diffusion cell (FDC) to evaluate the aceclofenac release profile from each formulation. Dialysis membrane was mounted on the Franz diffusion cell. Phosphate buffer of saline (PBS) $\mathrm{pH} 7.4$ was used as the receptor medium $(12 \mathrm{ml})$ being stirred at $700 \mathrm{rpm}$. NLC dispersion (equivalent to $1 \mathrm{mg}$ of aceclofenac) was placed in the donor compartment. During the experiments the solution in the receptor side was maintained at $37 \pm 0.5^{\circ} \mathrm{C}$ at predetermined time intervals, $1 \mathrm{ml}$ of the samples were withdrawn from the receiver compartment and replaced by the same volume of freshly prepared PBS ( $\mathrm{pH} 7.4$ ) to maintain the sink condition. The samples were analyzed by the UV spectrophotometer at $273 \mathrm{~nm}$.

\section{Preparation and evaluation of aceclofenac loaded NLC gel. ${ }^{10,11}$}

The suitable NLC formulation for the topical delivery of aceclofenac was selected based on the evaluation characteristics like: particle size, entrapment efficiency and in vitro release. It was found that the formulation F 1 is more suitable among the other formulations. Carbopol was used as gelling agent and it was dispersed 
Table 1. Composition of Nano structured Lipid Carrier dispersion:.

\begin{tabular}{|c|c|c|c|c|c|c|}
\hline \multicolumn{8}{|c|}{ Table 1. Composition of Nano structured Lipid Carrier dispersion: } \\
\hline Composition & NF 1 mg & NF 2 mg & NF 3 mg & NF 4 mg & NF 5 mg & NF 6 mg \\
\hline Aceclofenac & 40 & 40 & 40 & 40 & 40 & 40 \\
\hline Oleic acid & 50 & 75 & 100 & 50 & 15 & 100 \\
\hline Stearic acid & 200 & 200 & 200 & 150 & 150 & 150 \\
\hline Phospho lipon G & 0.030 & 0.030 & 0.030 & 0.030 & 0.030 & 0.030 \\
\hline Tween 80 & 2 & 2 & 2 & 2 & 2 & 2 \\
\hline
\end{tabular}

in the NLC dispersion using a mechanical stirrer at a speed of $1200 \mathrm{rpm}$. The dispersion was neutralized using triethanolamine. The gel was allowed to stand overnight to remove entrapped air.

\section{Scanning Electron Microscope (SEM)}

The particle sizes of the Nano lipid carrier formulations NF1 were viewed and photographed using scanning electron microscope (HITACHI S- 3000 H, SEM operated at $20 \mathrm{kv}$ ). The sample preparation for SEM is follow as. The sample was transferred to a glass slide which was cut in the dimension of $20 \times 20 \mathrm{~mm}$, which is then were mounted on an aluminum stub using double sided carbon tape. The solution was added a drop on the glass slide and slowly evaporated at room temperature. The completely dried sample was coated with gold by sputter coating unit at 10 Pascal vacuum for $10 \mathrm{sec}$ to a thickness of $100 \AA$ using HITACHI evaporator. The image was captured on SEM mode at desired magnification.

\section{Stability Studies}

The conditions affecting the physical and chemical stability of lipid nanoparticles were evaluated. The first condition was performed at $25^{\circ} \mathrm{C} \pm 2{ }^{\circ} \mathrm{C} / 60^{\circ} \mathrm{C} \pm 5 \%$ $\mathrm{RH}$ for 6 months as per $\mathrm{ICH}$ guidelines. The $\mathrm{pH}$, viscosity and drug release was determined periodically every month.

\section{Evaluation parameters of Nanostructured Lipid carrier topical gel: ${ }^{12,13}$ \\ Consistency and clarity}

After preparation, the gel formulations were visually inspected by naked eyes. The consistency and clarity of the gel formulations were observed.

\section{pH determination}

The $\mathrm{pH}$ of the gel formulation was measured using digital $\mathrm{pH}$ meter. The gel formulations were diluted in ratio 1:25 using distilled water. Standard buffer solution of $\mathrm{pH} 4,7$ and 10 were used for calibration of $\mathrm{pH}$ meter. The gel formulation was tested in triplicate to obtain mean $\mathrm{pH}$ value. The diluted gel was in contact with $\mathrm{pH}$ electrode for 10 minu to allow the $\mathrm{pH}$ values to stabilize. The electrode was thoroughly washed between each sample.

\section{Drug content uniformity ${ }^{14,15}$}

Fixed quantity (40 mg) of the gel samples were accurately weighed into a $10 \mathrm{ml}$ volumetric flask. After suitable dilution with the phosphate buffered saline of $\mathrm{pH} 7.4$, the sample was then subjected to sonication for about 10 min to effect complete extraction of the drug. Volumes were made then to $10 \mathrm{ml}$ and then these stock solutions were filtered and further diluted. Absorbance of the solutions was measured at $273 \mathrm{~nm}$ in U.V visible spectrophotometer.

\section{Rheology}

Viscosity was determined by Brook field LDV prime I viscometer model. The gel sample was taken in a beaker and the dial reading was noted at $100 \mathrm{rpm}$ for $60 \mathrm{sec}$ with spindle no CP 52 at the temperature of $30^{\circ} \mathrm{C}$. Viscosity of the gel was measured and was tabulated.

\section{Spreadability}

Spread ability is one of the important characteristic for topical formulation as far as patient compliance is concerned. It was determined by placing one gm of gel between the two glasses slides on to which weights were allowed to rest. The top slide was subjected to pull of $100 \mathrm{gm}$ weight. The time in seconds required for the top slide to travel $100 \mathrm{~cm}$ distance gives relationship of spread ability of gel. The result was tabulated in the Table 3.

\section{RESULTS AND DISCUSSION}

The Aceclofenac loaded NLCs were formulated using different concentrations of solid lipid and liquid lipid by the melt dispersion ultrasonication technique as shown in Table 1. Out of six formulations (NF1) seems to exhibit good physical stability indicated by high entrapment efficiency value as shown in the Figure 1 and Table 2. The drug release profile from the NF1 displayed a biphasic drug release pattern with burst release at the initial stage followed by sustained release as shown in 
Table 2: Shows the Mean particle Size Drug content\% Entrapment Efficiency:

\begin{tabular}{|c|c|c|c|}
\hline NF1 & $360.36 \pm 1.20$ & $13.56 \pm 1.65$ & 87.59 \\
\hline NF2 & $275.5 \pm 10.15$ & $18.22 \pm 1.23$ & 80.11 \\
\hline NF3 & $170.65 \pm 5.70$ & $19.45 \pm 1.89$ & 89.25 \\
\hline NF4 & $185.55 \pm 10.25$ & $17.52 \pm 1.74$ & 78.35 \\
\hline NF5 & $140.23 \pm 3.26$ & $19.56 \pm 1.78$ & 82.56 \\
\hline NF6 & $440.56 \pm 6.08$ & $18.11 \pm 1.45$ & \\
\hline
\end{tabular}

\begin{tabular}{|c|c|}
\hline \multicolumn{2}{|c|}{ Table 3: shows the parameters of gel and Observa- } \\
tionsi \\
\hline Parameters & Observation \\
\hline Homogeneity & Good \\
\hline $\mathrm{pH}$ & $5.56 \pm 0.57$ \\
\hline Drug content & $96.42 \pm 0.60$ \\
\hline Viscosity ( cPs) & 8370 \\
\hline Spread ability & $22.72 \mathrm{gm} \mathrm{cm} / \mathrm{sec}$ \\
\hline
\end{tabular}

the Figure 2. These results indicated that the NF1 is a suitable carrier of aceclofenac with improved drug loading capacity and sustained drug release properties. The Scanning Electron microscope (SEM) shows the particles of the NF1 formulations were round and spherical in shape as shown in Figure 3.

Therefore, NF1 was selected and the nanostructured based gel containing aceclofenac was formulated by using the gelling agent Carbopol 934. The drug content of the gel was clearly shown the Figure 4. It has been observed that NLC gel produces the gel with good consistency, homogeneity, spreadability and rheological behavior as shown the Table 3. It was found that NLC gel showed a biphasic release pattern, and provided a

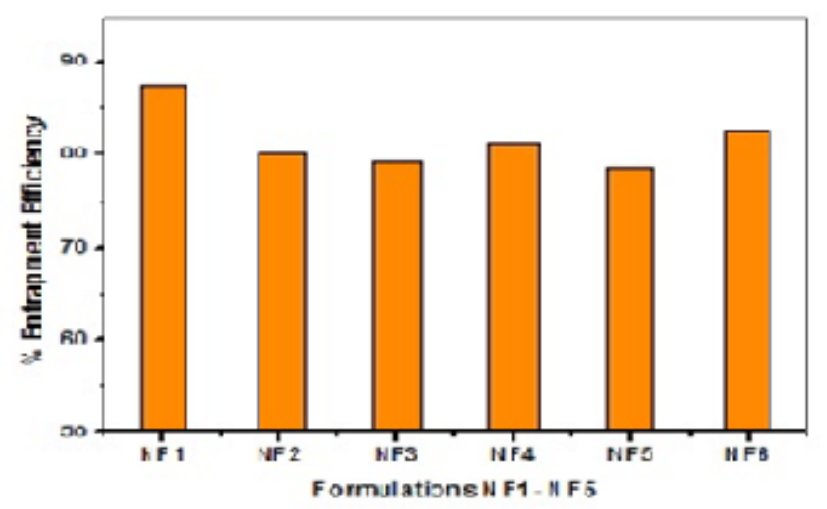

Figure 1: Entrapment Efficiency of all the formulations NF1NF5.

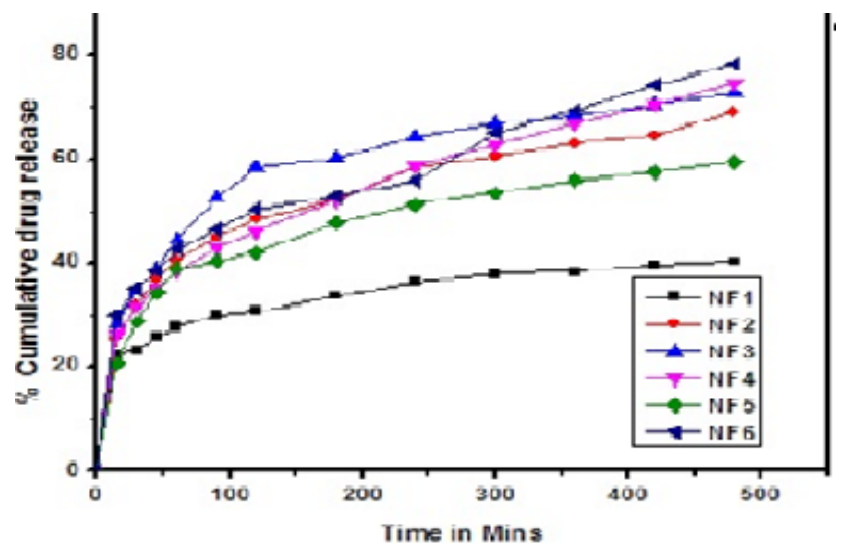

Figure 2: \% Cumulative drug release studies of all formulations NF1-NF5.

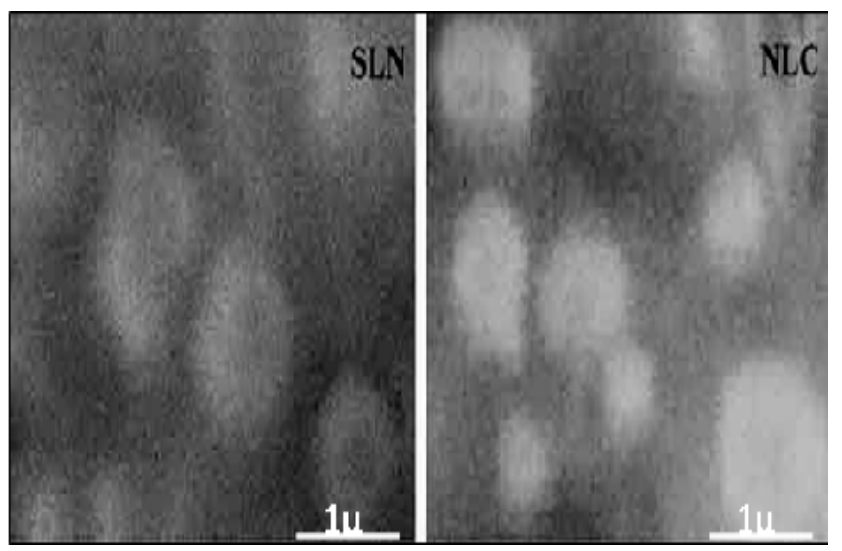

Figure 3: SEM images of SLN and NLC formulations. Shows the spherical in shape and discrete..

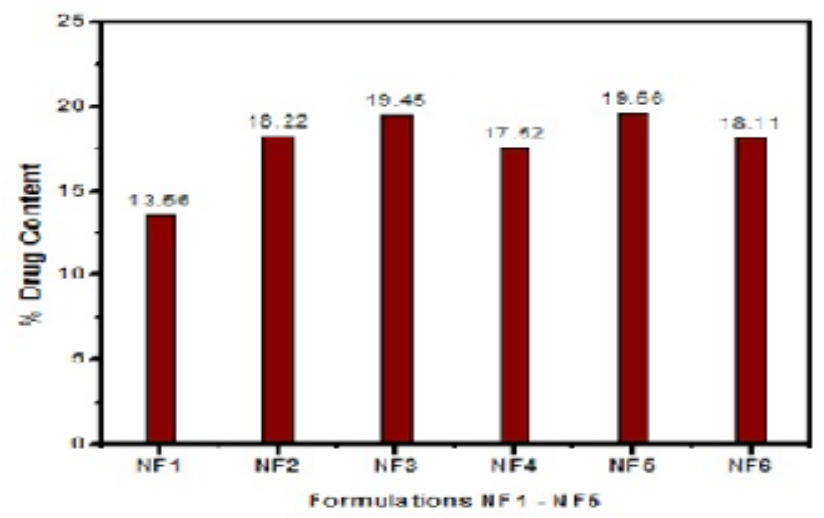

Figure 4: Drug content of the formulations NF1-NF5 
fast release initially for skin saturation followed by a slow and prolonged release profile to maintain the skin concentration.

The present study concluded that the NLC-based gel containing aceclofenac dissolved in a mixture of solid lipid and liquid lipid in the nanoparticulate form helped us to attain the objective of faster onset yet prolonged action as evident from in vitro release profile.

\section{CONCLUSION}

Nanostructured lipid carriers were prepared by ultra sonication method by using stearic acid, oleic acid, phospholipon $\mathrm{H}$ and Tween 80. FTIR studies proved no interaction between drug, polymer and between the formulations. The particle size of the prepared NLC was suitable for topical application. The mean diameter of the particle and entrapment efficiency increased with increase in the lipid concentration also Aceclofenac release studies were dependent upon the size of the nanoparticles. Hence drug loaded topical gel was prepared which would be a promising drug delivery for transdermal application.

\section{ACKNOWLEDGEMENT}

Our sincere thanks to our College Sri Ramachandra Medical College and Research Institute for the support and the facilities provided for the project.

\section{CONFLICT OF INTEREST}

Authors have no conflict of interest in publishing this research work.

\section{ABBREVIATIONS}

NLC: Nanostructured Lipid Carriers; SLN: Solid Lipid Nanoparticles; NSAID: Non-Steroidal Anti Inflammatory Drug; GI: Gastro intestinal; EE: Entrapment Efficiency; FT-IR: Fourier Transforms-Infra Red; UV-Vis:
Ultra Violet - Visible; DL: Drug Loading; FDC: Franz Diffusion Cell; PBS: phosphate Buffer Solution; SEM: Scanning Electron Microscope; ICH: International Conference on Harmonization.

\section{REFERENCES}

1. Rahul N, Vishnu priya K, Arun Kumar KS, Badivaddin TM, Sevukarajan M. Formulation and Evaluation of solid lipid nanoparticles of water soluble drug: Isoniazid. JPSR. 2011;3(5):1256-64.

2. Singh S, Dobhal AK, Jain A, Pandit JK, Chakrabroty S. Formulation and evaluation of solid lipid nanoparticles of a water soluble drug: Zidovudine. Chem Pharm Bull. 2010;58(5):650-5.

3. Anand Kumar K, Parameswara Rao V, Priyanka K, Sanjay Kumar S, Sanjay S. Development and Evaluation of solid lipid nanoparticles of Raloxifene Hydrochloride for Enhanced Bioavailability. BioMed Res. Int. 2013.

4. Pinto MF, Moura CC, Nunes C, Segundo MA, Lima SA, Reis S, et al. A new topical formulation for psoriasis: Development of methotrexate- loaded nanostructured lipid carriers. Int. J. Pharm. 2014;477(1-2):519-26.

5. Dandagi PM, Dessai GA, Gadad AP, Desai VB. Formulation and Evaluation of nanostructured lipid Carrier (NLC) of Lornoxicam. Int J Pharm Pharm Sci. 2014;6(2):73-7.

6. Jameel Ahmed M, Nitinkumar S, Panchamukhi SI, Khazi Imtiyaz Ahmed M. Formulation, Characterization and in-vitro Evaluation of novel Thienopyrimidines and Triazolothienopyrimidines loaded Solid Lipid Nanoparticles. IJRAP. 2010;1(1):192-200.

7. Dubey A, Prabhu P, Kamath JV. Nano Structured lipid carriers: A Novel Topical drug delivery system. Int J Pharm Tech Res. 2012;4(2):705-14.

8. Patel D, Dasgupta S, Dey S, Roja Ramani Y, Ray S, Mazumder B. Nanostructured lipid Carriers (NLC) - Based Gel for the Topial Delivery of Aceclofenac: Preparation, Characterization and In-vitro Evaluation. Sci. Pharm. 2012;80(3):749-64.

9. Uner L, Yener G3. "Importance of Solid Lipid Nanoparticles (SLN) in various administration routes and future perspectives," Int. J. Nanomed. 2007:2(3):289-300.

10. Byrav PDS, Medhi B, Prakash A, Patyar S, Wadhwa S. Lornoxicam: A Newer NSAID, IJPMR. 2009;20(1);27-31.

11. Schwarz C, Mehnert W. Solid lipid nanoparticles (SLN) for the controlled compound delivery. II. Compound incorporation and physicochemical characterization. J Microencapsul. 1998;45(2):149-55.

12. Wissing $S$, Lippacher A, Muller R. Investigations on the occlusive properties of solid lipid nanoparticles (SLN), J Cosmet Sci, 2001;52(5):313-24.

13. Goodman LS, Gilman A, Rall TW, Nies AS, Taylor P. Analgesic-antipyretics and anti-inflammatory agent; drug employed in the treatment of rheumatoid McGraw-Hill International edition, New York. 1922;636-81.

14. Nasr M, Mansour S, Mortada ND, Shamy AA. Lipospheres as carriers for Topical Delivery of Aceclofenac: Preparation, Characterization and in vivo Evaluation. AAPS PharmSciTech, 2008;9(1):154-62.

15. Lee J, Lee Y, Kim J, Yoon M, Choi WY. Formulation of micro emulsion system for transdermal delivery of aceclofenac. Arch Pharm Res. 2005;28(9):1097102.

\section{About Authors}

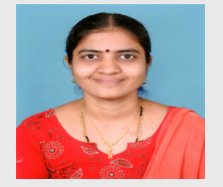

S. Nagalakshmi: I am an academician, aspiring to excel in the field of novel drug delivery system, especially in the area of ocular, transdermal and targeted drug delivery. My current doctoral research work aims to develop a novel ocular delivery system which had strengthened as my proficiency in this area to acquire extramural grants.

S. Shanmuganathan: I am an academician, aspiring to excel in novel advanced drug delivery and tissue engineering research. My doctoral and Post Doctoral research experience in targeted drug delivery, wound healing, tissue repair had strengthened me towards acquiring extra mural grants for expanding my research in proposed fields. 


\section{PICTORIAL ABSTRACT}

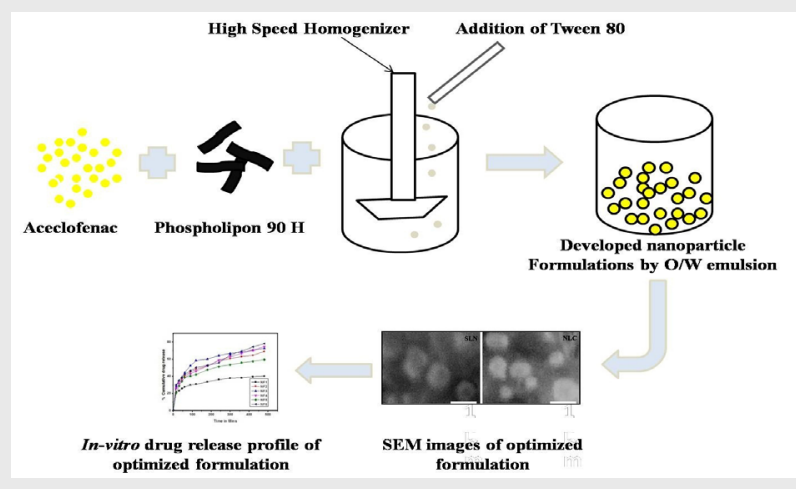

\section{SUMMARY}

Nano structured lipid carriers are novel carriers in recent trends. Hence the developed formulation is a better alternate to conventional formulation by virtue of prolonged action, avoiding side effect, reducing dosage frequency producing better therapeutic effect and hence better patient compliance.

Cite this article: Naglakshmi S, Shanmuganathan S, Sandhya K, Anbarasan B. Design, Development and Characterization of Nano Structured Lipid Carrier for Topical Delivery of Aceclofenac. Indian J of Pharmaceutical Education and Research. 2018;52(4):581-6. 